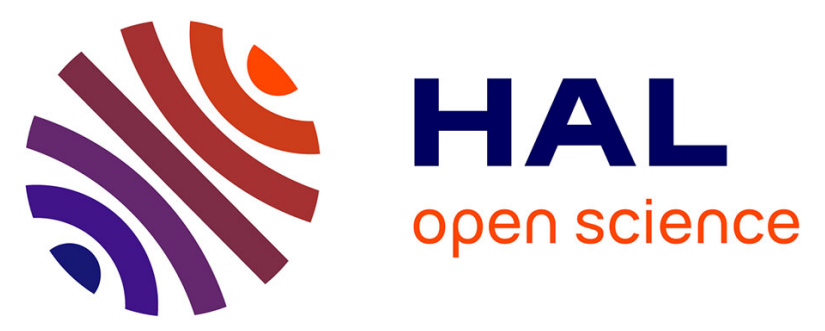

\title{
Spin Crossover Metal-Organic Frameworks with Inserted Photoactive Guests: On the Quest to Control the Spin State by Photoisomerization
}

\author{
Barbora Brachňaková, Ján Moncol, Ján Pavlik, Ivan Šalitroš, Sébastien \\ Bonhommeau, Francisco Javier Valverde-Muñoz, L. Salmon, Gábor Molnár, \\ Lucie Routaboul, Azzedine Bousseksou
}

\section{To cite this version:}

Barbora Brachňaková, Ján Moncol, Ján Pavlik, Ivan Šalitroš, Sébastien Bonhommeau, et al.. Spin Crossover Metal-Organic Frameworks with Inserted Photoactive Guests: On the Quest to Control the Spin State by Photoisomerization. Dalton Transactions, 2021, 50 (25), pp.8877-8888. 10.1039/D1DT01057C . hal-03285860

\section{HAL Id: hal-03285860 https://hal.science/hal-03285860}

Submitted on 13 Jul 2021

HAL is a multi-disciplinary open access archive for the deposit and dissemination of scientific research documents, whether they are published or not. The documents may come from teaching and research institutions in France or abroad, or from public or private research centers.
L'archive ouverte pluridisciplinaire HAL, est destinée au dépôt et à la diffusion de documents scientifiques de niveau recherche, publiés ou non, émanant des établissements d'enseignement et de recherche français ou étrangers, des laboratoires publics ou privés. 


\section{Spin Crossover Metal-Organic Frameworks with Inserted Photoactive Guests: On the Quest to Control the Spin State by Photoisomerization}

Barbora Brachňaková,a,b Ján Moncol',b Ján Pavlik,b Ivan Šalitroš,b,c,d* Sébastien Bonhommeau, ${ }^{e}$ Francisco Javier Valverde-Muñoz, ${ }^{\mathrm{f}}$ Lionel Salmon, ${ }^{\mathrm{a}}$ Gábor Molnár, ${ }^{\mathrm{a}}$ Lucie Routaboul, a Azzedine Bousseksou ${ }^{a^{*}}$

a) LCC, CNRS \& Université de Toulouse, 205 route de Narbonne, 31077 Toulouse, France b) Department of Inorganic Chemistry. Faculty of Chemical and Food Technology. Slovak University of Technology in Bratislava. Bratislava SK-81237, Slovakia.

c) Department of Inorganic Chemistry. Faculty of Science, Palacký University, 17. listopadu 12, 77146 Olomouc, Czech Republic

d) Central European Institute of Technology, Brno University of Technology, Purkyňova 123, 61200 Brno Czech Republic

e) Univ. Bordeaux, CNRS, Bordeaux INP, ISM, UMR 5255, F-33400 Talence, France

f) Departament de Quimica Inorgànica, Institut de Ciencia Molecular (ICMol), Universitat de Valencia, Valencia, Spain.

*E-mail: ivan.salitros@stuba.sk, azzedine.bousseksou@lcc-toulouse.fr

Abstract. Three Hofmann-like metal-organic frameworks $\{\mathrm{Fe}(\mathrm{bpac})[\mathrm{Pt}(\mathrm{CN}) 4]\} \cdot \mathrm{G}$ (bpac=1,2-bis(4-pyridyl)acetylene) were synthesized with photoisomerizable guest molecules ( $\mathrm{G}=$ trans-azobenzene, trans-stilbene or cis-stilbene) and were characterized by elemental analysis, thermogravimetry and powder X-ray diffraction. The insertion of guest molecules and their conformation were inferred from Raman and FTIR spectra and from single-crystal X-ray diffraction and confronted with computational simulation. The magnetic and photomagnetic behaviors of the framework are significantly altered by the different guest molecules and different conformations. On the other hand, photoisomerization of the guest molecules becomes strongly hindered by the framework.

\section{INTRODUCTION}

Since their discovery nearly a century ago, spin crossover (SCO) complexes of transition metal ions have been extensively studied due to their unique optical, magnetic, electrical and mechanical properties related to the switching between the low spin (LS) and high spin (HS) electronic configurations. ${ }^{1}$ The spin state of these compounds can be modified by various external stimuli such as variation of temperature, pressure, intense magnetic fields, adsorption/desorption of molecules and light irradiation. SCO molecules with the ability to "switch" their properties show appealing application potential in several fields of technology such as information processing devices, sensors and actuators. ${ }^{2}$ In this context, light irradiation appears as a fascinating tool for the control of physical properties 
of SCO materials. It is well known that photoexcitation can change the population of the LS and HS states via ligand-field or charge transfer transitions and subsequent relaxation phenomena. $^{3}$ In certain compounds, at very low temperatures, the photoinduced metastable spin state can have a very long lifetime (days-weeks). This famous phenomenon is known in the literature as the Light-Induced Excited Spin State Trapping (LIESST) and was already reported for many ferrous SCO compounds and for a few ferric complexes as well. ${ }^{4}$ However, the low temperature that is necessary for the trapping of the photoexcited states can be a drawback for applications. An alternative way to control the spin state of SCO compounds by light is the introduction of photoswitchable ligands capable of reversible transformation between two isomeric forms when exposed to selective wavelengths. Obviously, this photoconversion results in modifications of both the ligand field and the crystal packing and therefore the relative stability of the HS and LS states of the central metal ion will be altered. The Ligand-Driven Light-Induced Spin Crossover (LD-LISC) approach, introduced by Zarembowitch et al., ${ }^{5}$ is a fascinating strategy because it can be performed even in ambient conditions. However, only a few compounds exhibit LD-LISC in the solid state and the associated SCO is usually not complete due to the significant steric hindrance for the photoisomerization of the ligands in the solid state. ${ }^{6}$

In analogy with the LD-LISC approach, one could also envision to encapsulate photoisomerizable guest molecules within porous metal-organic frameworks (MOFs) displaying SCO, leading to the novel concept of Guest-Driven Light-Induced Spin Crossover (GD-LISC). Indeed, in the past two decades several SCO-MOFs have been synthesized, the most famous being the Hofmann-type SCO clathrates, pioneered by the team of Real, ${ }^{7}$ with compositions $\{\mathrm{Fe}(\mathrm{L})[\mathrm{M}(\mathrm{CN}) 4]\}(\mathrm{M}=\mathrm{Ni}, \mathrm{Pt}, \mathrm{Pd}$; L = pyrazine, 4,4'bipyridine, 4,4'-azopyridine, 1,2-bis(4-pyridyl)ethylene, 1,2-bis(4-pyridyl)acetylene (bpac) and so forth). ${ }^{8}$ The SCO phenomenon in these three-dimensional (3D) porous systems is related to hexa-coordinated iron(II) centers interconnected to each other via the pillared organic ligand L in axial direction and via the diamagnetic tetracyanometallate ligand in equatorial directions. A remarkable property of these compounds is that their spin state can be controlled by the nature and quantity of inserted guest molecules (steric effect or ability to create short contact interactions). ${ }^{9-12}$ Tuning the SCO properties has been achieved also by the incorporation of 'active' guest molecules displaying chemical reactivity. ${ }^{12}$ In the case of photoisomerizable guest molecules, switching from one form to the other is associated with changes of the molecular geometry as well as various physical properties, such as the dielectric permittivity. Therefore, one can assume that photoisomerization should efficiently modulate the phase stability (and associated magnetic properties) of the host system via the modification of host-guest interactions.

Several papers have already reported about the introduction of various photochromic molecules into different MOFs and other macrocyclic cage systems and the photoisomerization of the encapsulated molecules have also been demonstrated. ${ }^{13,14}$ The aim of these works was the incorporation of switchable guests within a porous framework and the associated ability to photocontrol their functional properties, such as pore 
size, ${ }^{13 a, b}$ adsorption ability, ${ }^{13 c}$ optical ${ }^{13 d}$ or electric ${ }^{14 a}$ properties and solubility. ${ }^{14 b}$ However, to our best knowledge, the control of magnetic properties of a MOF by guest isomerization has not yet been reported.

In the present work, we examined the mutual effect of an SCO-MOF and photoisomerizable molecules on their respective switching properties. Specifically, we report on the synthesis and characterization of the Hofmann-like framework $\left\{\mathrm{Fe}(\mathrm{bpac})\left[\mathrm{Pt}(\mathrm{CN})_{4}\right]\right\} \cdot \mathrm{G}$ with different photoisomerizable guest molecules $(\mathrm{G}=$ transazobenzene, trans-stilbene or cis-stilbene). We show that the presence of different guest molecules leads to different magnetic and photomagnetic properties of the host framework, depending on the nature and molecular conformation of the guest molecules. On the other hand, the host network introduces constraint for the photoisomerization of the guest molecules, which mostly extent in their initial configuration.

\section{EXPERIMENTAL SECTION}

Materials and characterization. Solvents and reagents, including $\mathrm{K}_{2}\left[\mathrm{Pt}(\mathrm{CN})_{4}\right] \cdot 3 \mathrm{H}_{2} \mathrm{O}$, $\mathrm{Fe}\left(\mathrm{BF}_{4}\right) \cdot 6 \mathrm{H}_{2} \mathrm{O}$, trans-azobenzene, trans-stilbene and cis-stilbene, were purchased form Sigma-Aldrich and used without further purification. The preparation of the bpac ligand and the host framework $\left\{\mathrm{Fe}(\mathrm{bpac})\left[\mathrm{Pt}(\mathrm{CN})_{4}\right]\right\} \cdot 1.5 \mathrm{H}_{2} \mathrm{O} \cdot 0.5 \mathrm{bpac}$ was carried out according to Ref. $[8 \mathrm{e}, 15]$. Elemental analysis for $\mathrm{CHN}$ were performed after combustion at $850{ }^{\circ} \mathrm{C}$, using IR detection and gravimetry, by means of a Perkin-Elmer 2400 series II device. MidIR spectra of the powders were acquired between $4000-600 \mathrm{~cm}^{-1}$ in ATR mode using a Perkin Elmer FTIR Frontier spectrometer. UV-VIS spectra of the solutions were acquired between 800 - $200 \mathrm{~nm}$ in transmission mode using a Cary 60 spectrophotometer. Irradiation of the stilbene solution was carried out using a $150 \mathrm{~W}$ xenon light source and a UV bandpass filter (275-375 $\mathrm{nm})$. Thermogravimetry (TG) measurements were performed in a nitrogen flow at a heating rate of $5 \mathrm{Kmin}^{-1}$ in a Netzsch STA $409 \mathrm{C}$ analyzer. Powder X-ray diffraction (PXRD) patterns of the samples have been collected using a Panalytical MPD XPertPro diffractometer [CuKa1 source, Ge(111) monochromator, $\mathrm{X}^{\prime}$ Celerator detector] within the $2 \theta$ range $2-60^{\circ}$.

Synthesis of $\left\{\mathrm{Fe}(\mathrm{bpac})\left[\mathrm{Pt}(\mathrm{CN})_{4}\right]\right\}$-trans-azobenzene $(1$ and $1 \mathrm{~b})$. $\mathrm{K}_{2}\left[\mathrm{Pt}(\mathrm{CN})_{4}\right] \cdot 3 \mathrm{H}_{2} \mathrm{O}(100 \mathrm{mg}, 0.23 \mathrm{mmol}, 1.0 \mathrm{eq})$ and equivalent amount of transazobenzene ( $42 \mathrm{mg}, 0.23 \mathrm{mmol}, 1.0 \mathrm{eq}$ ) were dissolved in $30 \mathrm{~cm}^{3}$ water-methanol mixture (1:1). Dropwise addition of water-methanol mixture $\left(1: 1,30 \mathrm{~cm}^{3}\right)$ with dissolved bpac (42 $\mathrm{mg}, 0.23 \mathrm{mmol}, 1.0 \mathrm{eq})$ and $\mathrm{Fe}\left(\mathrm{BF}_{4}\right)_{2} \cdot 6 \mathrm{H}_{2} \mathrm{O}(78 \mathrm{mg}, 0.23 \mathrm{mmol}, 1.0 \mathrm{eq})$ led to the formation of an orange colored solution that was stirred under Ar atmosphere for 2 hours at room temperature (RT). The experimental apparatus was not protected against daylight. The precipitated orange powder 1 was filtered off and washed with water $\left(5 \mathrm{~cm}^{3}\right)$, methanol $\left(5 \mathrm{~cm}^{3}\right)$ and diethyl ether $\left(5 \mathrm{~cm}^{3}\right)$. The same synthetic procedure was repeated to obtain compound 1b. Single-crystals suitable for X-ray diffraction analysis were obtained by slow crystallization in H-tube. 8 e $\mathrm{Fe}\left(\mathrm{NH}_{4}\right)_{2}\left(\mathrm{SO}_{4}\right)_{2} .6 \mathrm{H}_{2} \mathrm{O}(30.5 \mathrm{mg}, 0.07 \mathrm{mmol}, 1.0 \mathrm{eq})$ and bpac (14 mg, $0.07 \mathrm{mmol}, 1.0 \mathrm{eq}$ ) were dissolved in $4 \mathrm{~cm}^{3}$ water:ethanol mixture (1:1) and poured into one side of the $\mathrm{H}$-tube and the other side was filled by $\mathrm{K}_{2}\left[\mathrm{Pt}(\mathrm{CN})_{4}\right] \cdot 3 \mathrm{H}_{2} \mathrm{O}(33.3$ 
mg, $0.07 \mathrm{mmol}, 1.0 \mathrm{eq})$ dissolved in $2 \mathrm{~cm}^{3}$ water. The system was finally filled by a water:ethanol (1:1) solution of azobenzene (14 mg, $0.07 \mathrm{mmol}, 1.0 \mathrm{eq})$. After 10 weeks small, thin, square-shaped, red crystals were obtained. Elemental analysis for $\left\{\mathrm{Fe}(\mathrm{bpac})\left[\mathrm{Pt}(\mathrm{CN})_{4}\right]\right\} \cdot$ trans-azobenzene $\left(\mathrm{C}_{28} \mathrm{H}_{20} \mathrm{FeN}{ }_{8} \mathrm{OPt}, M_{\mathrm{w}}=717.43 \mathrm{~g} \cdot \mathrm{mol}^{-1}\right)$, found \% (expected \%) for 1: C 45.79 (46.88), N 15.57 (15.62), H 1.84 (2.53); and for 1b: C 45.80 (46.88), N 15.52 (15.62), H 1.96 (2.53). FTIR ( $\tilde{V}_{\max } / \mathrm{cm}^{-1}$ ) for 1: 2165 (s, CN), 1609, 1548 (m, C-Car and $\mathrm{C}_{\mathrm{ar}}-\mathrm{N}$ ), 1484, 1453, 1421 (m, $\mathrm{C}_{\mathrm{ar}}-\mathrm{N}$ and/or C-Car); and for 1b: 2166 (s, CN), 1609, 1547 (m, C-Car and Car-N), 1484, 1454, 1421 (m, Car-N and/or C-Car).

Synthesis of $\left\{\mathrm{Fe}(\mathrm{bpac})\left[\mathrm{Pt}(\mathrm{CN})_{4}\right]\right\} \cdot \mathrm{H}_{2} \mathrm{O} \cdot$ trans-stilbene $(2$ and $\mathbf{2 b})$. $\mathrm{K}_{2}\left[\mathrm{Pt}(\mathrm{CN})_{4}\right] \cdot 3 \mathrm{H}_{2} \mathrm{O}(100 \mathrm{mg}, 0.23 \mathrm{mmol}, 1.0 \mathrm{eq})$ and trans-stilbene (45.6 mg, $0.25 \mathrm{mmol}$, $1.1 \mathrm{eq})$ were dissolved in a water-ethanol mixture $\left(1: 2,40 \mathrm{~cm}^{3}\right)$. The solution was stirred under Ar atmosphere for 30 minutes at RT and a water-ethanol mixture $\left(1: 1,20 \mathrm{~cm}^{3}\right)$ with dissolved $\mathrm{Fe}\left(\mathrm{BF}_{4}\right)_{2} \cdot 6 \mathrm{H}_{2} \mathrm{O}$ (78.0 mg, $0.23 \mathrm{mmol}, 1.0 \mathrm{eq}$ ) and bpac (42 mg, $0.23 \mathrm{mmol}, 1.0$ eq) was added dropwise. The experimental apparatus was not protected against daylight. After 2 hours of stirring, the yellow solid product 2 was filtered off and washed with water $\left(5 \mathrm{~cm}^{3}\right)$, methanol $\left(5 \mathrm{~cm}^{3}\right)$ and diethyl ether $\left(5 \mathrm{~cm}^{3}\right)$. The same synthetic procedure was repeated to obtain compound $\mathbf{2 b}$. Elemental analysis for $\left\{\mathrm{Fe}(\mathrm{bpac})\left[\mathrm{Pt}(\mathrm{CN})_{4}\right]\right\} \cdot \mathrm{H}_{2} \mathrm{O} \cdot$ transstilbene $\left(\mathrm{C}_{30} \mathrm{H}_{22} \mathrm{FeN}_{6} \mathrm{OPt}, M_{\mathrm{w}}=733.46 \mathrm{~g} \mathrm{~mol}^{-1}\right)$, found \% (expected \%) for 2: C 49.94 (49.13), N 10.88 (11.46), H 2.17 (3.02); and for 2 b: C 50.18 (49.13), N 11.07 (11.46), H 2.28 (3.02). FTIR ( $\tilde{\mathrm{V}}_{\max } / \mathrm{cm}^{-1}$ ) for 2: $2163(\mathrm{~s}, \mathrm{CN}), 1609,1546\left(\mathrm{~m}, \mathrm{C}-\mathrm{C}_{\mathrm{ar}}\right.$ and $\left.\mathrm{Car}_{\mathrm{r}} \mathrm{N}\right), 1497$, 1452, 1420 (m, Car-N and/or C-Car); and for 2b: 2164 (s, CN), 1609, 1547 (m, C-Car and CarN), 1497, 1453, 1421 (m, Car-N and/or C-Car).

Synthesis of $\left\{\mathrm{Fe}(\mathrm{bpac})\left[\mathrm{Pt}(\mathrm{CN})_{4}\right]\right\} \cdot 2.3 \mathrm{H}_{2} \mathrm{O} \cdot 0.6 \mathrm{cis}$-stilbene $(3$ and $3 \mathrm{~b})$. $\mathrm{K}_{2}\left[\mathrm{Pt}(\mathrm{CN})_{4}\right] \cdot 3 \mathrm{H}_{2} \mathrm{O}(100 \mathrm{mg}, 0.23 \mathrm{mmol}, 1.0 \mathrm{eq})$ and cis-stilbene $\left(0.9 \mathrm{~cm}^{3}, 0.50 \mathrm{mmol}, 2.2\right.$ eq) were dissolved in a water-ethanol mixture $\left(1: 2,30 \mathrm{~cm}^{3}\right)$ and stirred under $\mathrm{Ar}$ atmosphere over 30 minutes at RT. Then, a water-ethanol mixture $\left(1: 2,30 \mathrm{~cm}^{3}\right)$ with dissolved $\mathrm{Fe}\left(\mathrm{BF}_{4}\right)_{2} \cdot 6 \mathrm{H}_{2} \mathrm{O}$ (78.0 mg, $0.23 \mathrm{mmol}, 1.0 \mathrm{eq}$ ) and bpac (42 mg, $0.23 \mathrm{mmol}, 1.0$ eq) was added dropwise. The experimental apparatus was not protected against the daylight. The suspension was stirred for 2 hours and the yellow solid product $\mathbf{3}$ was then filtered off and washed with ethanol $\left(10 \mathrm{~cm}^{3}\right)$ and diethyl ether $\left(10 \mathrm{~cm}^{3}\right)$. The same synthetic procedure was repeated to obtain compound $\mathbf{3 b}$. Elemental analysis for

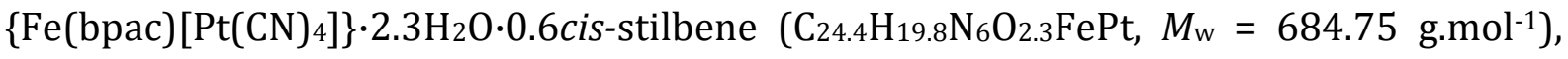
found \% (expected \%) for 3: C 42.02 (42.79), N 9.06 (12.27), H 1.69 (2.91); and for 3b: C 43.80 (42.79), N 10.04 (12.27), H 1.85 (2.91). FTIR ( $\tilde{V}_{\max } / \mathrm{cm}^{-1}$ ) for $3: 2165$ (s, CN), 1609, 1546 (m, C-Car and $\mathrm{C}_{a r}-\mathrm{N}$ ), 1495, 1448, 1443, 1421 (m, $\mathrm{C}_{\mathrm{ar}}-\mathrm{N}$ and/or C-Car); and for $\mathbf{3 b}$ : 2165 (s, CN), 1609, 1547 (m, C-Car and Car-N), 1494, 1949, 1443, 1421 (m, Car-N and/or Car-Car).

Post-synthetic guest insertion experiments. Compounds 1c-3c with transazobenzene, trans-stilbene and cis-stilbene guests, respectively, have been synthesized by the inclusion of the guest molecules into the cavities of the previously synthesized host framework $\left\{\mathrm{Fe}(\mathrm{bpac})\left[\mathrm{Pt}(\mathrm{CN})_{4}\right]\right\} 1.5 \mathrm{H}_{2} \mathrm{O} \cdot 0.5$ bpac in $1: 1$ ratio in an ethanol-water mixture $\left(1: 1,20 \mathrm{~cm}^{3}\right)$. The mixture was stirred under Ar atmosphere at RT for 24 hours, filtered off and dried by $10 \mathrm{~cm}^{3}$ diethyl ether. 
Single-crystal X-ray diffraction analysis. Data collection and cell refinement of $\mathbf{1}$ at 100 and $180 \mathrm{~K}$ were made using a Stoe StadiVari diffractometer. The diffractometer was equipped with an HPAD detector (Pilatus3R 300K) and a microfocused X-ray source (Xenocs Genix3D Cu HF). The programs ShelXT, ShelXL (ver. 2018/3), OLEX2 and MERCURY have been used for structure determination, refinement, finalization and drawing. ${ }^{16}$

Computational details. All calculations were performed using the program ORCA 4.2.0.17a-b The effect of encapsulation of azobenzene and stilbene isomers was studied by the QM/MM strategy as follows: an electrically neutral cut off from the low-spin and highspin MOF cavity was defined (Fig. SI-8), which was considered a rigid body and treated by molecular mechanics (MM), whereas the encapsulated molecule was subject of geometrical optimization, vibrational and Raman analysis employing quantum mechanics (QM). The geometry of cavities was fixed as resulted from X-ray analysis except of positions of hydrogen atoms, which were optimized by the method PBEh-3c. ${ }^{17 c}$ Precise orientation of molecule of trans-azobenzene was known from the X-ray analysis, all other molecules were manually put in similar position and optimized. The additive coupling and electrostatic embedding schemes were used. The charges at MOF atoms were obtained by the CHELPG method ${ }^{17 d}$ after a successfully converged DFT calculation. This was performed with the GGA functional PBE ${ }^{17 e}$ and the def2-SVP basis ${ }^{17 f}$ for all atoms, except of Pt for which the effective core potential def2-ECP17g was used. The Coulomb term was treated by the resolution of identity approach (RI-J) ${ }^{17 \mathrm{~h}}$ with the Coulomb fitting basis set def2/J.17i Increased integration grid was used (grid7 in ORCA convention). Since all metallic centres are structurally equivalent, in ideal case the values of CHELPG charges should be equal for all Pt atoms and Fe atoms. Obviously, this will not be obeyed for a finite-size cavity. Comparison of calculated values of CHELPG charges shows that smaller error is introduced in the case of LS cavity where all values are closer to each other (Fig. SI-9). The geometry of the embedded molecules was optimized using the same GGA functional PBE and a higher-quality basis def2-TZVP18f with the same approximation to the Coulomb term as mentioned above. No negative vibration frequencies were found. The Raman spectra were calculated within a development version of ORCA 4.2.

Raman spectroscopy. Raman measurements were carried out in backscattering geometry using commercial, confocal Raman microspectrometers (Horiba Scientific), including a Labram HR Evolution spectrometer (focal length $\mathrm{f}=800 \mathrm{~mm}$, grooves density $\mathrm{G}=2400 \mathrm{~mm}^{-1}$, objective magnification $\mathrm{m}=5 \mathrm{x}$, laser excitation wavelength $\lambda=355 \mathrm{~nm}$ and power $\mathrm{P}=0.9 \mathrm{~mW}$ ), an XploRA spectrometer $\left(\mathrm{f}=250 \mathrm{~mm}, \mathrm{G}=1200 \mathrm{~mm}^{-1}\right.$ or $2400 \mathrm{~mm}^{-1}$, $\mathrm{m}=100 \mathrm{x}$ or $50 \mathrm{x}, \lambda=785$ or $532 \mathrm{~nm}, \mathrm{P}=0.4$ or $1 \mathrm{~mW}$, respectively) and a Labram HR800 spectrometer $\left(\mathrm{f}=800 \mathrm{~mm}, \mathrm{G}=600 \mathrm{~mm}^{-1}, \mathrm{~m}=50 \mathrm{x}, \lambda=532 \mathrm{~nm}, \mathrm{P}=1 \mathrm{~mW}\right)$. The frequency calibration was systematically performed by checking the $520 \mathrm{~cm}^{-1}$ Raman mode of a reference Si sample. Standard deviations on wavenumbers were lower than $1 \mathrm{~cm}^{-1}$. The sample temperature was set using a Linkam THMS600 liquid-nitrogen-cooled cryostage. Owing to the microcrystalline nature of the analyzed samples the polarization dependence of the spectra was not investigated. 
Magnetic and photomagnetic experiments. Magnetic property measurements were performed using a MPMS-XL7 and a PPMS VersaLab instrument (Quantum Design). For magnetic susceptibility measurements in the dark, the temperature dependent magnetization was recorded under an external magnetic field of $0.1 \mathrm{~T}$ at sweeping rates of $\pm 1 \mathrm{~K} \mathrm{~min}^{-1}$. The data were corrected for the diamagnetic contributions. Photomagnetic measurements were performed using a diode-pumped solid-state laser Kvant $(\lambda=637$ $\mathrm{nm}, 300 \mathrm{~mW}$ ) coupled through an optical fiber to the cavity of the magnetometer. The power on the sample was adjusted to $10 \mathrm{mWcm}^{-2}$. For the photomagnetic experiments, a small amount of sample $(\approx 1 \mathrm{mg})$ was diluted in melted eicosane, introduced into the measuring plastic straw and solidified. The weight of the samples was obtained by comparison with the thermal $\chi T$ vs. $T$ curve of a more accurately weighed sample of the same compound. After cooling to $5 \mathrm{~K}$, the sample was irradiated and the change in magnetization was followed. After reaching the saturation point, the light was switched off, the temperature was increased at a rate of $0.3 \mathrm{~K} \mathrm{~min}^{-1}$ and the magnetization was measured at $1 \mathrm{~K}$ intervals. The so-called $T$ (LIESST) value ${ }^{18}$ was determined as the temperature for which the $\partial(\chi T) / \partial T$ vs. $T$ derivative function reaches a minimum.

\section{RESULTS AND DISCUSSION}

\subsection{Synthesis of the host-guest systems}

For the present work we have chosen the $\left\{\mathrm{Fe}(\mathrm{bpac})\left[\mathrm{Pt}(\mathrm{CN})_{4}\right]\right\}$ clathrate network, ${ }^{8 \mathrm{e}, 15}$ which exhibits thermal SCO near room temperature with hysteresis. The large pore size in this system (ca. $300 \AA^{3}$ in the denser LS state) allows relatively bulky guest molecules to be hosted. Notably, photoisomerizable molecules, such as azobenzene and stilbene, whose size roughly matches the size of the cavities, can be incorporated a priori. This can provide the scope for the light-induced modulation of the spin state of the host framework due to the trans-cis photoisomerization of the guest molecules.

Azobenzene and stilbene (and their derivatives) are well-known photochromic molecules with various applications. ${ }^{19-21}$ These molecules are able to undergo reversible interconversion between the trans (E) and cis (Z) isomers induced by light or by thermal activation. The switching from the trans to the cis form can be induced by ultraviolet light in both compounds, whereas the reverse conversion is achieved by visible (resp. UV) light for azobenzene (resp. stilbene) or by heating. It is important to note that the isomerization of azobenzene (resp. stilbene) is associated with the variation of planarity of guest molecules as well as with the change in their lengths by ca. $2.9 \AA$ (resp. $2.3 \AA$ ) and volume by ca. $3.7 \AA^{3}$ (resp. $1.0 \AA^{3}$ ). The guest molecules in the trans conformation may create a sandwiched or slipped stacking with the pillared bpac ligands and build intermolecular interactions. ${ }^{8 e, 12}$ Obviously, when going from the trans to the cis configuration, the loss of planarity leads to altered interactions with the host framework. ${ }^{12 c}$

We tested different approaches, which were reported in the literature ${ }^{15}$ for the synthesis of $\left\{\mathrm{Fe}(\mathrm{bpac})\left[\mathrm{Pt}(\mathrm{CN})_{4}\right]\right\}$ with guest molecules. It turned out that the building of the host network in the presence of guest molecules (compounds 1-3 and $\mathbf{1 b}-\mathbf{3 b}$ ) seems to be the most favorable strategy to maximize the inclusion of photochromic guests and 
minimize the quantity of uncoordinated bpac molecules within the cavities of the host. Although the presence of trans-azobenzene (1c), trans-stilbene (2c) and cis-stilbene (3c) is also visible in the vibrational spectra following post-synthetic inclusion of guests, the fingerprint of uncoordinated bpac ligand in 1c-3c is also detected around $1599 \mathrm{~cm}^{-1}$ and $997 \mathrm{~cm}^{-1}$ in the FTIR and Raman spectra, respectively (see Fig. SI-1 in the Supporting Information, SI). For this reason, we focused our attention mostly on the investigation of compounds 1-3 and 1b-3b. The quantity of included guests in the different clathrates was estimated by combination of elemental analysis and thermogravimetric measurements (see Fig. SI-2) which resulted in molecular formula $\left\{\mathrm{Fe}(\mathrm{bpac})\left[\mathrm{Pt}(\mathrm{CN})_{4}\right]\right\} \cdot$ transazobenzene ( $\mathbf{1}$ and $\mathbf{1 b}),\left\{\mathrm{Fe}(\mathrm{bpac})\left[\mathrm{Pt}(\mathrm{CN})_{4}\right]\right\} \cdot \mathrm{H}_{2} \mathrm{O} \cdot$ trans-stilbene (2 and $\left.\mathbf{2 b}\right)$ and $\left\{\mathrm{Fe}(\mathrm{bpac})\left[\mathrm{Pt}(\mathrm{CN})_{4}\right]\right\} \cdot 2.3 \mathrm{H}_{2} \mathrm{O} \cdot 0.6$ cis-stilbene $(3$ and $\mathbf{3 b}$ ). The TG profile of the host network is comparable with the literature ${ }^{8 \mathrm{e}}$ and indicates the stability of each host-guest system up to $370 \mathrm{~K}$. The azobenzene clathrate exhibits a single abrupt mass loss above $500 \mathrm{~K}$ attributed to the liberation of trans-azobenzene molecules, whereas the stilbene clathrates exhibit mass loss in two steps. The first step is assigned to release of water molecules and takes place above $370 \mathrm{~K}$, while the second step above $450 \mathrm{~K}$ is related to the release of bpac molecules.

\subsection{Identification of the guest molecules in the host framework}

Different thermal stability of compounds 1-3, revealed by the TG measurements, is a first indication of the successful introduction of the three different guest molecules in the cavities of the frameworks. Infrared absorption and Raman scattering spectroscopies were used to confirm their presence and assess their configuration. The infrared absorption peaks of compounds 1-3 have been confronted with the FTIR spectra of the host clathrate and pure guest molecules (see Fig. 1 and Tab. SI-3). The FTIR spectrum of the host compound $\left\{\mathrm{Fe}(\mathrm{bpac})\left[\mathrm{Pt}(\mathrm{CN})_{4}\right]\right\} \cdot 1.5 \mathrm{H}_{2} \mathrm{O} \cdot 0.5 \mathrm{bpac}$ contains an intense peak at 2170 $\mathrm{cm}^{-1}$ characteristic for the cyanide group. The spectral range between 1800 and $600 \mathrm{~cm}^{-1}$ is characteristic of the bpac ligand, whereas in the low frequency range $\left(<600 \mathrm{~cm}^{-1}\right)$ one would expect mostly vibrations associated with the $2 \mathrm{D}\left\{\mathrm{Fe}\left[\mathrm{Pt}(\mathrm{CN})_{4}\right]\right\}$ sheets. ${ }^{22}$ The spectrum of the host system involves two peaks at $1612 \mathrm{~cm}^{-1}$ and $1599 \mathrm{~cm}^{-1}$ that can be assigned to coordinated and uncoordinated bpac molecules, respectively. This indicates that the host framework contains uncoordinated guest bpac molecules. A small shift to $1609 \mathrm{~cm}^{-1}$ of the coordinated bpac is observed in compounds $\mathbf{1 - 3}$ and no signal of uncoordinated ligands is present. The vanishing of the $995 \mathrm{~cm}^{-1}$ peak in compounds 1-3 further supports the absence of clathrated bpac molecules. We can also note a small shift of the $1018 \mathrm{~cm}^{-1}$ IR peak (host system) to $1015 \mathrm{~cm}^{-1}$ (compound 1) and $1016 \mathrm{~cm}^{-1}$ (compounds $\mathbf{2}$ and $\mathbf{3}$ ), attributed to the breathing of coordinated bpac molecules, which indicates different interactions between the pillared ligand and the various guest molecules.

In the spectrum of 1 two peaks at 1484 and $1453 \mathrm{~cm}^{-1}$ can be assigned to the inplane bending of phenyl groups with trans configuration of azobenzene. ${ }^{23}$ A peak at 927 $\mathrm{cm}^{-1}$ corresponds to $\mathrm{C}-\mathrm{C}$ and $\mathrm{C}-\mathrm{C}-\mathrm{N}$ aromatic ring deformation vibrations, whereas the most intense peaks centered at 776 and $691 \mathrm{~cm}^{-1}$ are assigned to the out-of-plane $\mathrm{C}-\mathrm{C}$ and 
C-H vibrational modes of azobenzene aromatic rings. ${ }^{24}$ On the other hand, IR spectra of compounds $\mathbf{2}$ and $\mathbf{3}$ are comparable, with only a few peaks allowing the trans and cis configurations of stilbene to be distinguished from each other. Peaks at 1497 (resp. 1495) and 1452 (resp. 1448) $\mathrm{cm}^{-1}$ for compound 2 (resp. 3) are assigned to the in-plane C-H bending of aromatic ring of stilbene molecules. Below $1000 \mathrm{~cm}^{-1}$, the IR peak at $963 \mathrm{~cm}^{-1}$ indicates the presence of trans-stilbene in compound 2. Based on previous calculations, ${ }^{25}$ this peak can be assigned to the $\mathrm{C}-\mathrm{H}$ bending modes of the benzene ring. In contrast, cisstilbene shows a few specific features in compound 3, namely a peak at $922 \mathrm{~cm}^{-1}$ attributed to an out-of-plane $\mathrm{C}$-H bending of the aromatic ring, and two others at 777 and $751 \mathrm{~cm}^{-1}$ (also present in pure cis-stilbene) assigned to the aromatic ring deformation or torsional modes. ${ }^{25,26}$ These differences support the selective insertion of trans- and cisstilbene into the cavities without structural interconversion during the synthesis of MOFs.

This conclusion is also supported by UV-VIS absorption spectroscopy that was carried out to verify if isomerization of stilbene occurs under the reaction conditions used for the synthesis of $\mathbf{2}$ and 3. The water-ethanol solutions of pure trans- or cis-stilbene were stirred over 2 hours and the UV-VIS absorption spectra were collected (see Fig. SI4). These spectra show that absorption bands of trans-stilbene at 295 and $308 \mathrm{~nm}$ and cisstilbene at $277 \mathrm{~nm}$ remain unchanged over the whole experiment, thus indicating an excellent stability of the compounds in our synthesis conditions.

To gain further insight on the insertion of the guest molecules, Raman spectra of compounds 1-3 were collected and compared with spectra of pure guest molecules (see Fig. SI-5) and the host compound $\left\{\mathrm{Fe}(\mathrm{bpac})\left[\mathrm{Pt}(\mathrm{CN})_{4}\right]\right\} \cdot 1.5 \mathrm{H}_{2} \mathrm{O} \cdot 0.5 \mathrm{bpac}$ (see Tab. SI-6). Raman spectra of 1-3 excited at $532 \mathrm{~nm}$ display features similar to those observed in $\left\{\mathrm{Fe}(\mathrm{bpac})\left[\mathrm{Pt}(\mathrm{CN})_{4}\right]\right\} .^{22,27}$ The signature of guest molecules is visible in the $1000-1600 \mathrm{~cm}^{-}$ ${ }^{1}$ spectral range. The most intense Raman peaks of trans-azobenzene in $\mathbf{1}$ are centered at $1145,1438,1473$ and $1492 \mathrm{~cm}^{-1}$ and can be assigned to vibrational modes involving $\mathrm{C}-\mathrm{N}$, $\mathrm{N}=\mathrm{N}, \mathrm{N}=\mathrm{N}+\mathrm{C}-\mathrm{N}$ and $\mathrm{C}=\mathrm{C}+\mathrm{N}=\mathrm{N}$ stretches, respectively, as well as $\mathrm{CCH}, \mathrm{CNN}$ and NCC inplane bends. ${ }^{28}$ In addition, several weak peaks at $1186,1316 \mathrm{~cm}^{-1}$ and a shoulder at 1594 $\mathrm{cm}^{-1}$ are discernable. Raman spectra of $\mathbf{2}$ and $\mathbf{3}$ contain several intense peaks that can be assigned to stilbene guest molecules on the basis of literature data. ${ }^{25,29,30}$ An intense Raman peak, corresponding to vinyl $\mathrm{C}=\mathrm{C}$ stretching vibrations, appears for both isomers at ca. $1630 \mathrm{~cm}^{-1}$ (though less intense and redshifted in the cis isomer). This peak is a sensitive indicator of electronic delocalization in the molecule. In the pure cis and transstilbene samples, this mode is observed at 1629 and $1637 \mathrm{~cm}^{-1}$, respectively. In the host framework this mode is redshifted to ca. $1632 \mathrm{~cm}^{-1}$ for the trans conformer, whereas it remains nearly unchanged for the clathrated cis isomer. 

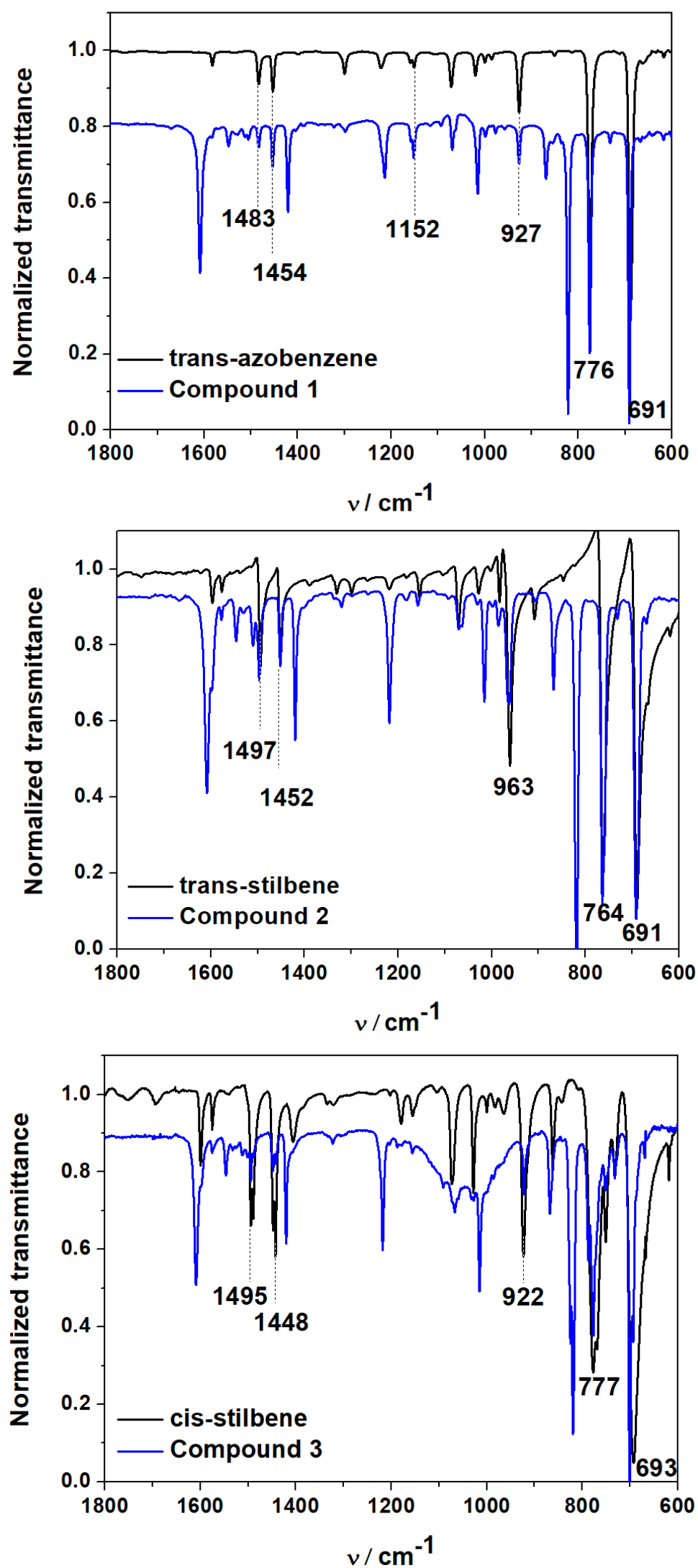

Figure 1. Room temperature FTIR spectral fingerprints of guest molecules in compounds 1-3. 
This is a compelling indication of intermolecular interactions between the bpac ligands and trans-stilbene guest molecules, resulting in a weaker $\mathrm{C}=\mathrm{C}$ bond due to its coupling to the aromatic rings by electronic delocalization. Two other intense peaks can be discerned at ca. $1595 \mathrm{~cm}^{-1}$ (assigned to $\mathrm{C}=\mathrm{C}$ ring stretching modes) and at $1191 \mathrm{~cm}^{-1}$ (assigned to C$\mathrm{H}$ bending modes of aromatic rings). ${ }^{25 a, 30}$ Other weak intensity peaks originating from stilbene were found between 1300 and $1500 \mathrm{~cm}^{-1}$ corresponding to $\mathrm{C}-\mathrm{H}$ bending and $\mathrm{C}=\mathrm{C}$ stretching vibrations of phenyl rings. ${ }^{30}$ One can differentiate the two isomers using a weak intensity peak at ca. $960 \mathrm{~cm}^{-1}$ (identified as in-phase ethylenic C-H out-of-plane wagging vibration $)^{30,31}$ which is only present in the cis configuration, due to its nonplanar structure.

In order to support the peak assignments, computer simulation of the encapsulation of photoisomerizable molecules was performed. The quantum mechanics/molecular mechanics method (QM/MM) was used. In this hybrid approach, a part of the studied system is selected, which is responsible for electronic properties and it is treated by the laws of quantum mechanics (QM). Rest of the system is a subject of classical Newtonian mechanics (molecular mechanics, MM). The MM part was defined here by cutoff from respective HS or LS host lattice (see Fig. SI-8) and its geometry was fixed rigid as it resulted from the X-ray study (vide infra). The QM part was formed by one of photoisomerizable guest molecules. The effect of host upon the geometry and vibrational behavior of guest molecules was mediated by electrostatic interactions (for more information see Computational details and ESI). The computed FTIR and Raman spectra of free and encapsulated guest molecules are shown in Fig. SI-7 and Tab. SI-10, SI-11. The overall agreement between the computed and experimental spectra is satisfactory, allowing us to extend and confirm the spectral assignments.

The presence of guest molecules in compound 1 was also confirmed by single crystal $\mathrm{X}$-ray diffraction analysis. The crystal structure was resolved at $100 \mathrm{~K}$ and $180 \mathrm{~K}$ in order to characterize the LS and HS states of the compound (vide infra). Selected crystallographic information are listed in Tab. SI-12. The insertion of trans-azobenzene changed the crystal symmetry compared to previously reported $\left\{\mathrm{Fe}(\mathrm{bpac})\left[\mathrm{M}(\mathrm{CN})_{4}\right]\right\}$-guest structures with uncoordinated bpac, toluene or 2,4,6trichlorophenol molecules, all crystallizing in the tetragonal $\mathrm{P} 4 / \mathrm{mmm}$ space group. ${ }^{8 \mathrm{e}}$ In the 100 - $180 \mathrm{~K}$ temperature range, compound 1 crystallizes in the triclinic P-1 space group. The thermal evolution of unit cell parameters (see Fig. SI-13) revealed a first-order phase transition accompanying the SCO with hysteresis and no change in the space group. This phase transition occurs above $165 \mathrm{~K}$ on the heating branch of the hysteresis loop and below $140 \mathrm{~K}$ on the cooling branch (see Fig. SI-13). Remarkably, while the $a$ and $b$ lattice constants increase with temperature $(\Delta a \approx+0.08 \AA, \Delta b \approx+0.24 \AA)$, the $c$ lattice constant notably decreases $(\Delta c \approx-0.36 \AA$ ) upon the SCO, resulting in a lattice volume expansion of $3 \%$, which is markedly smaller when compared to other $\left\{\mathrm{Fe}(\mathrm{bpac})\left[\mathrm{M}(\mathrm{CN})_{4}\right]\right\}$-guest structures. In both, the low- and high-temperature structures of $\mathbf{1}$, the unit cell involves one monomeric unit $\left\{\mathrm{Fe}(\mathrm{bpac})\left[\mathrm{Pt}(\mathrm{CN})_{4}\right]\right\}$-trans-azobenzene and the asymmetric unit contains half the iron(II) central atom, half the $\left[\mathrm{Pt}(\mathrm{CN})_{4}\right]^{2-}$ anion, and half bpac and transazobenzene molecules. The crystal structure of 1 consists of $2 \mathrm{D}$ inorganic $\left\{\mathrm{Fe}\left[\mathrm{Pt}(\mathrm{CN})_{4}\right]\right\}$ 
sub-layers which are interconnected through bpac bridging ligands (Fig. 2). The voids contain trans-azobenzene molecules situated between two bpac ligands in face-to-face fashion, albeit turned with respect to the direction of bpac pillars by ca. $34^{\circ}$ at $100 \mathrm{~K}$ and ca. $30^{\circ}$ at $180 \mathrm{~K}$ (see Fig. SI-14). Since the closest distances between two bpac and transazobenzene exceed $3.5 \AA$ A (see Fig. SI-14), guest molecules should form weak non-covalent contacts with neighbor bpac ligands from both sides. The closest intermolecular distance between two guest molecules is measured between the meta carbon atom of phenyl ring (C13) and the nitrogen atom (N4) of the azo bond (3.8137(1) $\AA$ at $100 \mathrm{~K}$ and 3.8787(2) $\AA$ at $180 \mathrm{~K})$. The Fe-N distances of the low temperature structure are $1.926(6) \AA$ (Fe-N1, FeN2) and 2.008(5) $\AA$ (Fe-N3), which is consistent with LS Fe(II) metal centers (see Fig. SI14). On the other hand, those bonds are notably longer 2.137(8) $\AA$ (Fe-N1), 2.153(8) $\AA$ (Fe-N2) and 2.217(9) Å (Fe-N3) at $180 \mathrm{~K}$ indicating HS Fe(II) centers. Furthermore, the thermal SCO affected several features of the supramolecular network. For instance, the C2-N2-Fe1 angle diminishes from $165.185(3)^{\circ}(100 \mathrm{~K})$ to $159.255(4)^{\circ}$ (180 K) due to the lengthening of the Fe-N2 bonds upon the SCO. The most apparent SCO-induced change of the supramolecular structure is observed on the $2 \mathrm{D}$ sub-layers $\left\{\mathrm{Fe}\left[\mathrm{Pt}(\mathrm{CN})_{4}\right]\right\}$, where the angle N1-C-Pt is $177.453(3)^{\circ}$ at $100 \mathrm{~K}$, but falls to $159.255(4)^{\circ}$ at $180 \mathrm{~K}$. The distances between the nearest Fe(II) atoms are 6.8681(2) $\AA$ (along the $a$-axis), 7.3161(2) $\AA$ (along the $b$-axis) and 13.6256(6) $\AA$ (along the $c$-axis) at $100 \mathrm{~K}$ and $6.9483(3) \AA$ (along $a$ axis), $7.5509(2) \AA$ (along $b$ axis) and 14.0040(6) $\AA$ (along $c$ axis) at $180 \mathrm{~K}$.

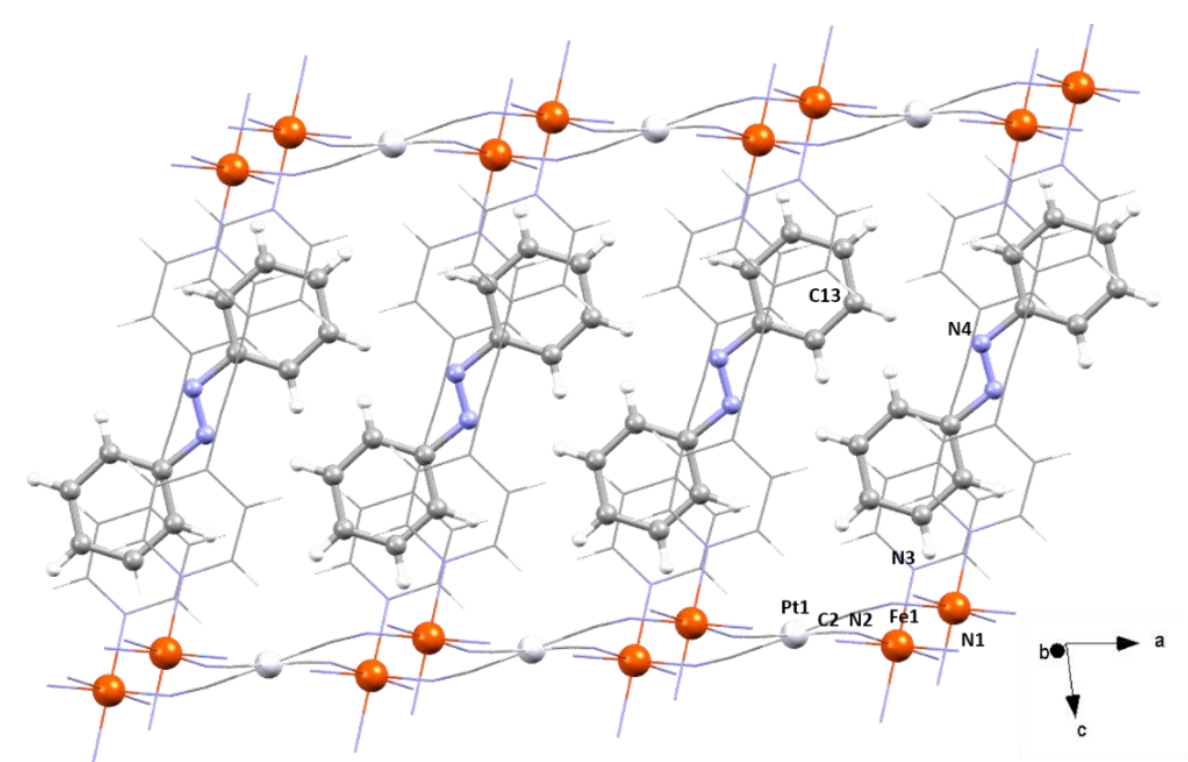

Figure 2. Supramolecular structure of compound 1. (Fe-orange, Pt-white, C-grey, N-blue, H-white.)

\subsection{Spin crossover properties of the host-guest compounds}

Some of us have previously reported on the effect of various guest molecules on the SCO properties of $\left\{\mathrm{Fe}(\mathrm{bpac})\left[\mathrm{Pt}(\mathrm{CN})_{4}\right]\right\}$. The empty host framework exhibits incomplete SCO situated just below room temperature, ${ }^{8 \mathrm{e}, 15}$ whereas the presence of uncoordinated bpac molecules (or other small aromatic molecules) in the cavities results in more complete near room temperature SCO associated with thermal hysteresis (see Fig. SI-15), whose 
width and position are strongly dependent of the number and the nature of guest molecules. ${ }^{8 e, 12 e, 32}$ It was shown that both electronic and steric interactions contribute to the SCO properties of the host-guest systems. ${ }^{33}$ Hence, one would naturally expect that the different photoisomerizable molecules used in the present study give rise to different SCO behaviours.

The temperature dependence (100-300 K) of the Raman spectra (532 nm excitation) was first used for the spectroscopic confirmation of the SCO properties of the samples. Indeed, the spectra show several changes when the molecules undergo SCO (Fig. 3). At $293 \mathrm{~K}$, the Raman peak at $1017 \mathrm{~cm}^{-1}$ for $\mathbf{1}\left(1014 \mathrm{~cm}^{-1}\right.$ for $\mathbf{2}$ or $\left.\mathbf{3}\right)$ can be assigned to the ring breathing of the coordinated bpac ligand. At $113 \mathrm{~K}$, the Fe(II) centers are partially converted to the LS state and a new peak at $1027 \mathrm{~cm}^{-1}$ appears for $\mathbf{1}\left(1026 \mathrm{~cm}^{-1}\right.$ for $\mathbf{2}$ and 3). The temperature dependence of the relative intensity of the $1017 \mathrm{~cm}^{-1}$ and $1027 \mathrm{~cm}^{-1}$ peaks allows for the identification of the temperature range for which the SCO occurs. The observed transition temperatures $\left(T_{1 / 2}\right)$ are ca. $135 \mathrm{~K}$ for $\mathbf{1}, 173 \mathrm{~K}$ for 2 and $162 \mathrm{~K}$ for 3 (see Fig. SI-16). In other words, the introduction of trans-azobenzene, cis-stilbene or trans-stilbene within the $\left\{\mathrm{Fe}(\mathrm{bpac})\left[\mathrm{Pt}(\mathrm{CN})_{4}\right]\right\}$ host matrix leads to a marked lowering (well below room temperature) of the temperature at which the SCO event occurs.

For a more quantitative investigation of the SCO properties, we acquired magnetic susceptibility data in two consecutive cooling-heating cycles for each sample (Fig. 4 and Fig. SI-17). Compound 1 exhibits a virtually complete, abrupt SCO with hysteresis. At 300 $\mathrm{K}$, the $\chi T$ product reaches a value of $3.81 \mathrm{~cm}^{3} \mathrm{Kmol}^{-1}$, which remains constant down to 150 $\mathrm{K}$. The subsequent drop of $\chi T$ around $T_{1 / 2} \downarrow=137 \mathrm{~K}$ indicates the SCO phenomenon. At 50 $\mathrm{K}$, the $\chi T$ product reaches a value of $0.35 \mathrm{~cm}^{3} \mathrm{Kmol}^{-1}$. Upon heating, the SCO occurs around $T_{1 / 2} \uparrow=148 \mathrm{~K}$, denoting a hysteresis width of ca. $11 \mathrm{~K}$. (N.B. The different transition temperatures observed in XRD experiments must arise most likely due to the different guest content of single crystal and powder samples.) Red-light irradiation ( $637 \mathrm{~nm})$ of the LS sample 1 was performed at $5 \mathrm{~K}$ and revealed an increase of the $\chi T$ value with time up to $0.86 \mathrm{~cm}^{3} \mathrm{Kmol}^{-1}$ (Fig. 4, red triangles). This is the sign that the compound exhibits LIESST effect. (N.B. This LS $\rightarrow$ HS photoswitching should not be confused with the photoisomerization of the guest, which is not possible in the red wavelength range!) Subsequent heating in the dark revealed a further increase of $\chi T$, which can be attributed to the zero-field splitting in HS Fe(II). ${ }^{12,32}$ The maximal $\chi T$ value of $1.52 \mathrm{~cm}^{3} \mathrm{Kmol}^{-1}$ was reached at $27 \mathrm{~K}$ denoting that ca. $1 / 3$ of the Fe centers have been photo-converted to the HS state (Fig. 4, white squares). Upon further heating, the thermally-induced relaxation from the photo-excited HS state back to the LS ground state takes place with a $56 \mathrm{~K}$ T(LIESST) temperature.

The introduction of trans- and cis-stilbene molecules into the cavities of $\left\{\mathrm{Fe}(\mathrm{bpac})\left[\mathrm{Pt}(\mathrm{CN})_{4}\right]\right\}$ leads also to dramatic changes in the SCO properties. Compounds 2 and 3 remain predominantly in the HS state, on cooling down to $224 \mathrm{~K}\left(\chi T=3.36 \mathrm{~cm}^{3} \mathrm{Kmol}^{-}\right.$ ${ }^{1}$ ) and $205 \mathrm{~K}\left(\chi T=2.84 \mathrm{~cm}^{3} \mathrm{Kmol}^{-1}\right)$, respectively. 

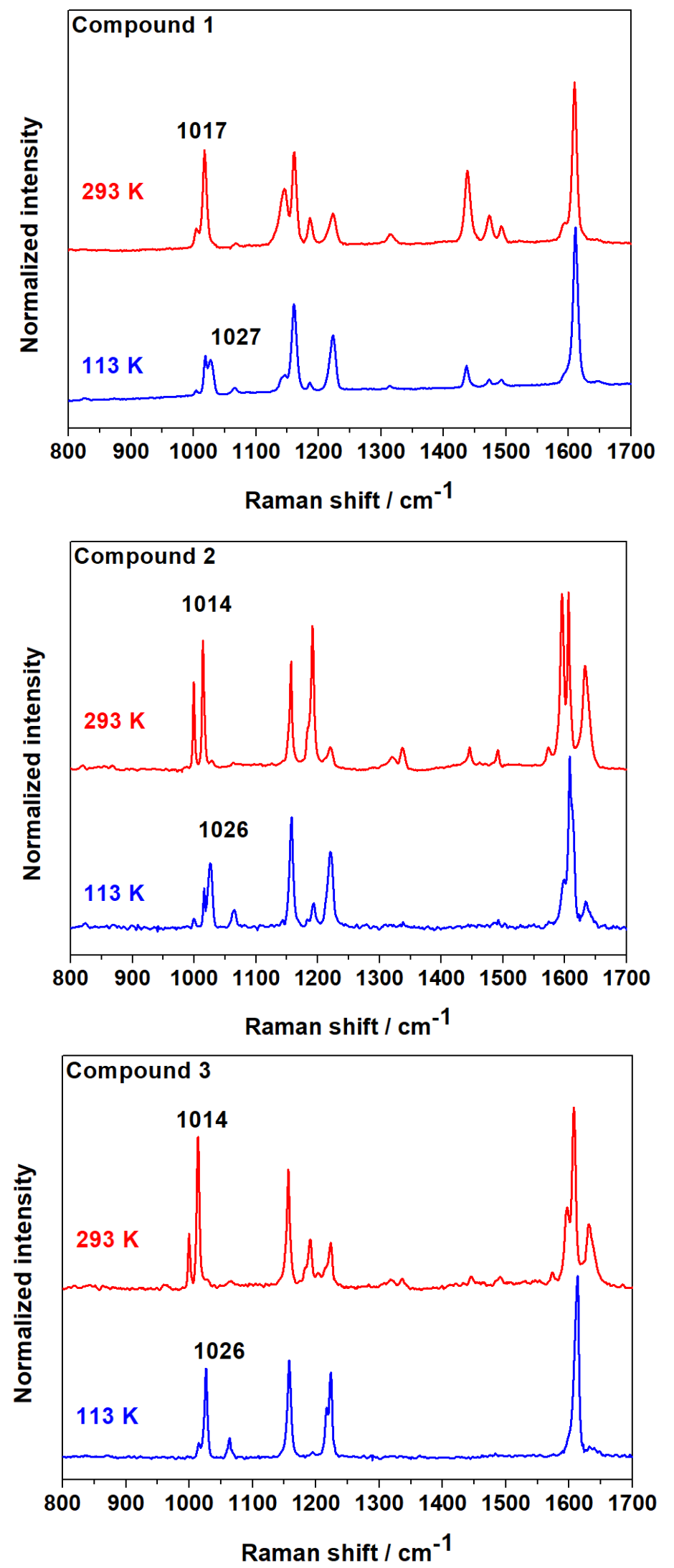

Figure 3. Raman spectra (532 nm excitation) of compounds 1-3 recorded at $293 \mathrm{~K}$ and $113 \mathrm{~K}$. 

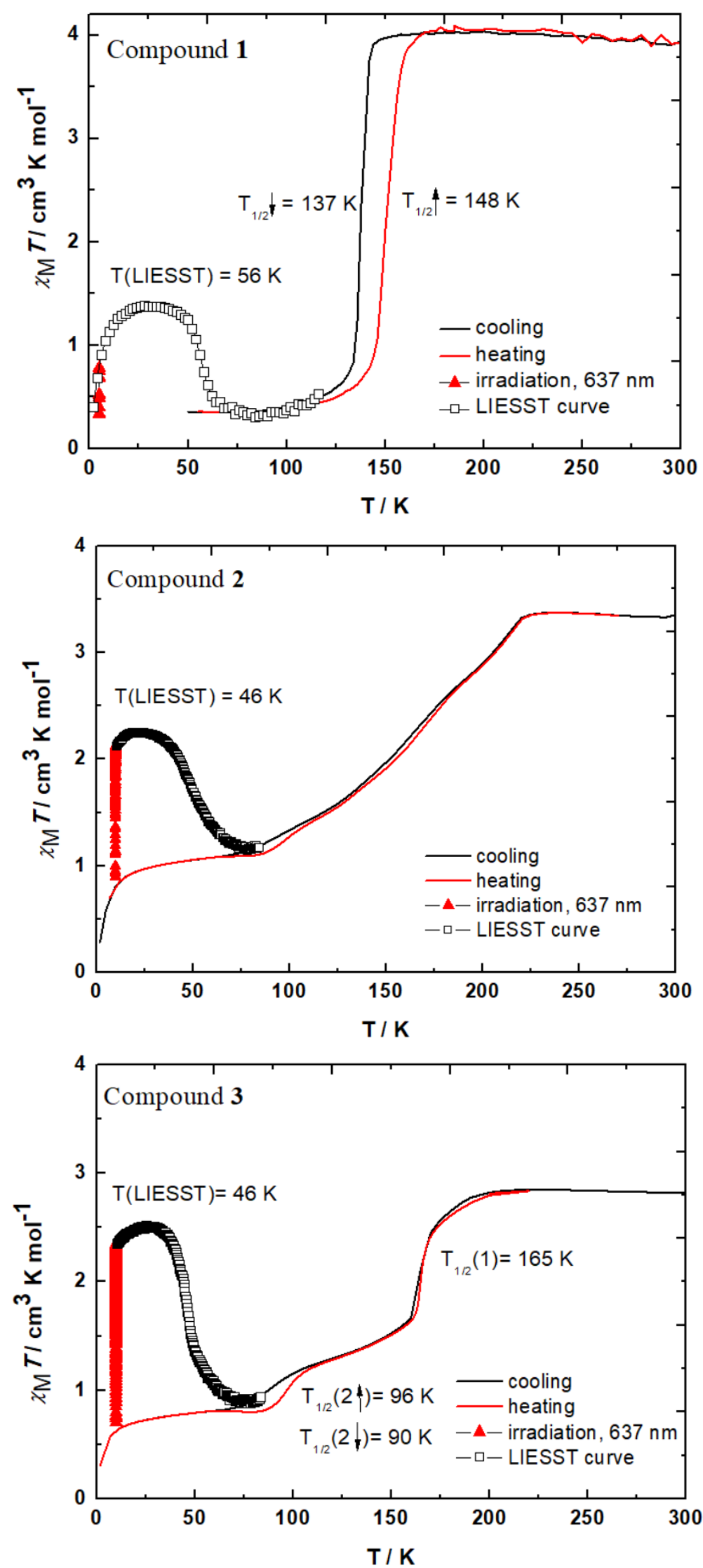

Figure 4. Magnetic properties ( $\chi T$ product) as a function of $T$ for compounds 1-3 on cooling and heating (solid lines). Photoexcitation by red light at $5 \mathrm{~K}$ or at $10 \mathrm{~K}$ (red triangles) and subsequent heating in the dark (white squares) is also shown. 
Further cooling revealed a stepwise SCO in both systems. Since the two steps of the SCO in $\mathbf{2}$ are gradual and not well separated, it is difficult to determine unambiguously the $T_{1 / 2}$ values for each step (Fig. 4). The low-temperature plateau reaches $\sim 1.0 \mathrm{~cm}^{3} \mathrm{~mol}^{-1} \mathrm{~K}$ corresponding to ca. $30 \%$ of molecules in the residual, 'frozen' HS state. The tiny hysteresis loop in the low temperature step of the transition has therefore likely a kinetic origin associated with slow relaxation (on the timescale of the magnetic measurements). Compound 3 exhibits also two-step SCO behavior between ca. 205 - $60 \mathrm{~K}$ (Fig. 4). The first transition is centered at $T_{1 / 2}(1)=165 \mathrm{~K}$ and associated with an abrupt decrease of $\chi T$ down to $1.52 \mathrm{~cm}^{3} \mathrm{Kmol}^{-1}$, which nearly corresponds to the $\chi T$ value expected for a $50 \%$ HS $\rightarrow$ LS conversion of the Fe(II) centers. The second and more gradual step is accompanied by kinetic effects and involves about $30 \%$ of the Fe(II) centers. The $\chi T$ value of the low-temperature plateau $\left(\sim 0.74 \mathrm{~cm}^{3} \mathrm{Kmol}^{-1}\right)$ indicates that ca. $25 \%$ of the Fe(II) centers remain trapped in the HS state. Red-light irradiation at $10 \mathrm{~K}$ led to an increase of the magnetic moment, denoting LIESST activity both in $\mathbf{2}$ and $\mathbf{3}$. The photoconversion is almost complete in $\mathbf{3}$ (90\% of HS centers at $27 \mathrm{~K}$ ) and remains largely incomplete in $\mathbf{2}$ (ca. $65 \%$ of HS centers at $22 \mathrm{~K}$ ), whereas the T(LIESST) temperatures are virtually the same for both compounds (ca. $46 \mathrm{~K}$ ).

In line with previous results, ${ }^{12,15}$ the strong decrease of the SCO temperature (i.e. the stabilization of the HS phase) most probably indicates that steric effects dominate the spin-transition behavior of the host-guest systems 1-3. It is tempting to associate the different SCO features in compounds $\mathbf{2}$ and $\mathbf{3}$ with the different conformation of stilbene guests (trans vs. cis). However, the differences could be also attributed (at least partly) to the different amount of guest molecules in the two samples. ${ }^{8 e, 12 c, 15}$ In order to better apprehend this issue, we prepared a second series of samples (1b-3b) under the same synthesis conditions, but somewhat with different final guest concentrations (see experimental section). FTIR, Raman and PXRD data confirmed the identity of both series of samples (see Fig. SI-18-20). The SCO behaviors of $\mathbf{1}$ and $\mathbf{1 b}$ appear comparable (see Fig. SI-17). On the other hand, the magnetic study of $\mathbf{2 b}$ and $\mathbf{3 b}$ revealed an increased residual HS fraction in the low temperature plateau (60\% for $\mathbf{2 b}$ and $50 \%$ for $\mathbf{3 b}$, see Fig. SI-17), albeit the shape of the SCO curves and the transition temperatures remain comparable with compounds 2 and 3. On the whole, whereas the concentration of inserted guest molecules has a clear impact on the SCO properties, these experiments show also that this parameter cannot explain alone the differences between the SCO behaviors of compounds $\mathbf{2}$ and $\mathbf{3}$. We can thus conclude that the insertion of cis- and transstilbene into the $\left\{\mathrm{Fe}(\mathrm{bpac})\left[\mathrm{Pt}(\mathrm{CN})_{4}\right]\right\}$ network leads to different thermal SCO and LIESST behaviors, thus providing the scope for light-induced modulation of spin states via GDLISC.

\subsection{Attempts for guest photoisomerization}

The literature reports several MOFs with incorporated optically active species and their successful switching in the solid state. ${ }^{33}$ However, the effective photoconversion in the solid state is not only hampered by steric hindrance and intermolecular interactions, but also by the strong UV absorption of the samples (host and guest comprised), which considerably reduces the light penetration depth $(\sim \mu \mathrm{m})$ in the relevant UV wavelength range (ca. $260-360 \mathrm{~nm}$ ). This results in very low apparent photoconversion yields in bulk 
samples (if the excited volume is too small relative to the analyzed one), and the light irradiation effects on the SCO properties are thus minor. In particular, our efforts to detect photoisomerization and associated magnetic property or structural changes on single crystal, powder or diluted powder samples were unsuccessful (see Fig. SI-21). In this context, UV Raman spectroscopy appears as a very relevant combined excitation/detection method. Not only does the focused laser beam provide high UV irradiance, but it also probes exclusively the photoexcited sample volume. In addition, $a$ priori, both the photoisomerization and SCO processes can be probed concomitantly. We thus acquired variable-temperature Raman spectra with the UV excitation wavelength $355 \mathrm{~nm}$ for samples 1-3 between 113 and $293 \mathrm{~K}$ (see Fig. SI-22). Spectra of the free guest molecules were also acquired as references and control Raman experiments under 532 and $785 \mathrm{~nm}$ light excitation were performed. (N.B. At these wavelengths no photoisomerization is expected.)

The UV Raman spectra of each sample present primarily resonance-enhanced modes of the guest molecules, whereas Raman peaks of the host framework are unfortunately hardly discernable. Based on literature data, ${ }^{28,34}$ in the trans-azobenzene sample (and therefore in compound $\mathbf{1}$ as well), the trans-cis isomerization should result in a marked shift of the intense $\mathrm{N}=\mathrm{N}$ stretching vibration from $1440 \mathrm{~cm}^{-1}\left(1433 \mathrm{~cm}^{-1}\right.$ in compound 1) to $1512 \mathrm{~cm}^{-1}$, which was not observed in our room-temperature UV Raman spectra. However, at lower temperatures, we observed the emergence of weak Raman peaks at $1506 \mathrm{~cm}^{-1}$ and $1135 \mathrm{~cm}^{-1}$ in compound $\mathbf{1}$, which could be ascribed to $\mathrm{N}=\mathrm{N}$ and C$\mathrm{N}$ stretches, respectively, of the cis conformer (see Fig. SI-23). Indeed, the metastable cis species is stabilized at low temperatures, where potential laser-induced heating effects on the sample are balanced.

In the case of the stilbene clathrates 2 and 3, the low temperature Raman spectra did not reveal any additional feature (see Fig. SI-22). Hence we restrict our discussion to the room temperature spectra, which are shown in Fig. 5 along with the spectra of the pure trans- and cis-stilbene samples acquired at different excitation wavelengths (see also Tab. SI-6 and SI-25). It is important to note that, in the case of stilbene, isomerization from trans to cis and vice versa can be achieved in solution by UV light, which we confirmed by spectrophotometric measurements (see Fig. SI-24). We must mention that the neat trans-stilbene sample is strongly fluorescent under $355 \mathrm{~nm}$ excitation, which prevents the UV Raman signature of this conformer to be discerned. However, the luminescence of trans-stilbene molecules is effectively quenched when they are inserted into the $\left\{\mathrm{Fe}(\mathrm{bpac})\left[\mathrm{Pt}(\mathrm{CN})_{4}\right]\right\}$ matrix. We shall also note here that recent studies have shown that stilbene derivatives may undergo cyclization under UV light leading to the formation of $4 \mathrm{a}, 4 \mathrm{~b}$-dihydrophenantrene and subsequent transformation to oxidized and more stable phenanthrene. However, our Raman spectra are not compatible with the formation of the cyclic product. ${ }^{35}$ In our experimental conditions, the most important spectral marker is the Raman peak around $965 \mathrm{~cm}^{-1}$, which is present only in the cis form due to spectral selection rules. ${ }^{31}$ Remarkably, under UV light excitation, neither compound $\mathbf{2}$ nor $\mathbf{3}$ display this Raman peak. Whereas solely this result does not consist of an irrefutable proof, it strongly indicates a sizeable cis to trans photoisomerization in 
compound 3. Unfortunately, the very weak intensity of the Raman signal from the host framework in the $355 \mathrm{~nm}$ Raman spectra of compound 3 did not allow us to probe the change of the SCO behavior of the host, which must accompany the cis to trans photoisomerization of the guest molecules at low temperatures.

(a)

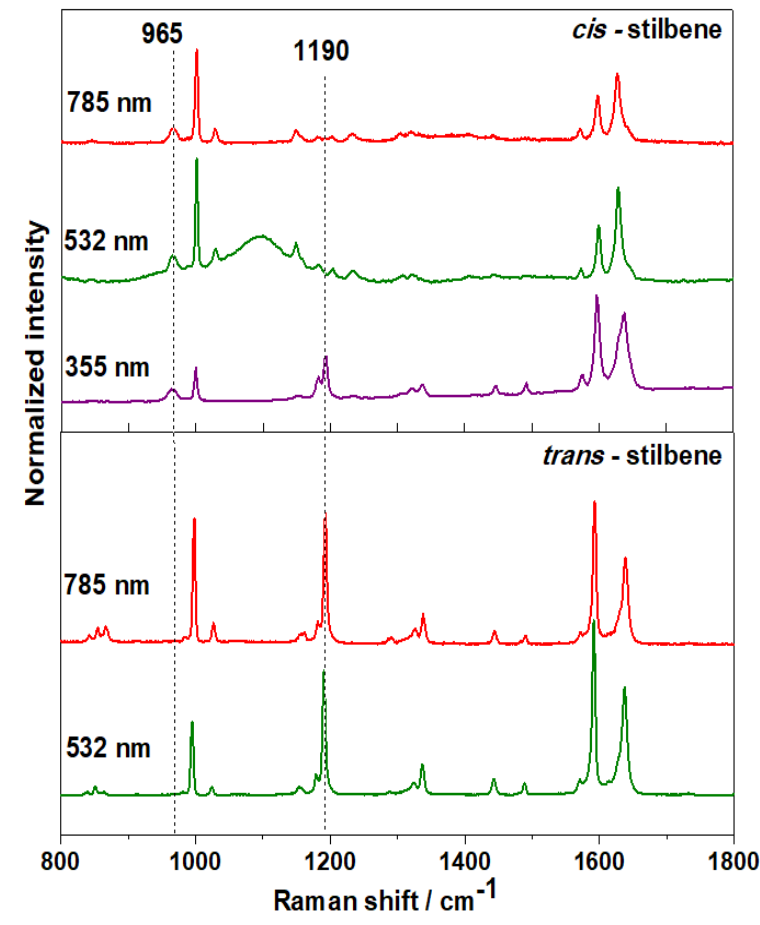

(b)

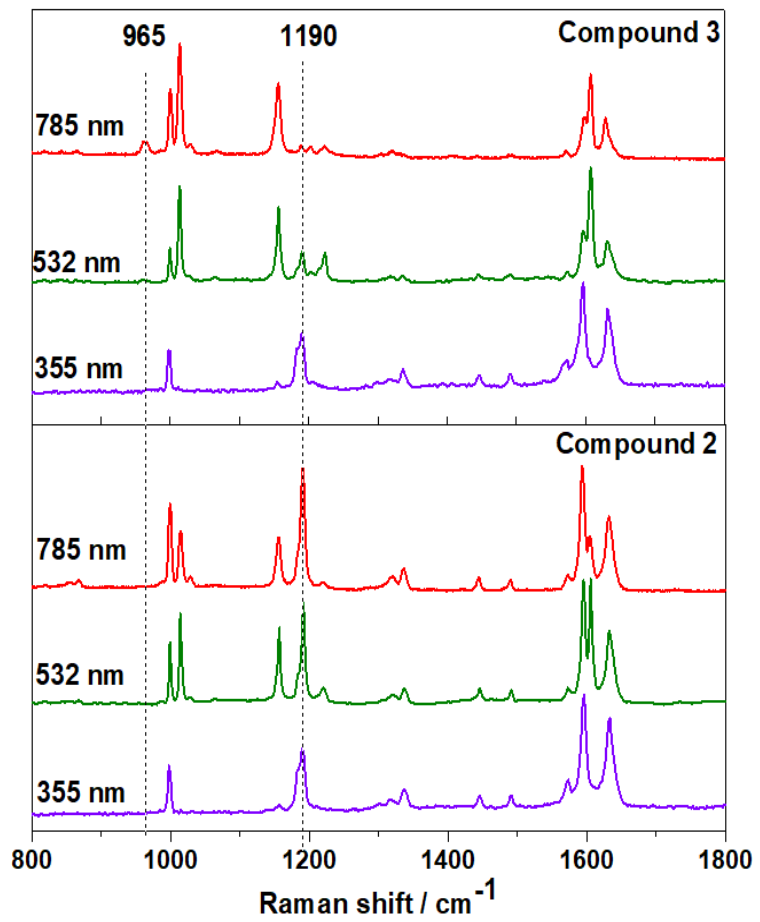

Figure 5. Room-temperature Raman spectra of (a) trans- (bottom) and cis-stilbene (top) obtained using different laser sources and (b) compound 2 (bottom) and compound 3 (top).

\section{CONCLUSION}

In this paper, we have investigated the mutual influence of photoisomerizable guest molecules and a host SCO-MOF framework on the switching properties of both the host and the guest. Single-crystal X-ray analysis, FTIR, Raman spectra and QM/MM simulation provided clear evidence for the successful insertion of trans-azobenzene, trans-stilbene and cis-stilbene molecules into $\left\{\mathrm{Fe}(\mathrm{bpac})\left[\mathrm{Pt}(\mathrm{CN})_{4}\right]\right\}$ frameworks. The magnetic and photomagnetic properties of the host framework were substantially modified through specific interactions with the different guest molecules. The drastic downshift of the spin transition temperatures in the presence of these guest molecules indicates that the SCO properties are altered via steric hindrance due to the bulky guest molecules. On the other hand, the different photoisomerization experiments were largely fruitless. Most likely, the steric hindrance and/or specific interactions with the host constitute an unsurmountable barrier for the photoconversion of the guest molecules within the host framework. Nevertheless, UV Raman experiments suggest that guest cis-stilbene molecules might be photoisomerized to some extent even inside the pores. This observation calls for further 
investigations, which should be extended for different host and guest systems (larger size of pores, guest activation by visible light or temperature), preferably in the form of thin films, in conjunction with adapted excitation/detection methods, such as multiplewavelength Raman spectroscopy.

\section{Conflict of interest}

To the best of our knowledge, there are no conflicts to declare

Acknowledgements. Slovak grant agencies are acknowledged for the financial support (APVV-18-0197, APVV-18-0016, APVV-19-0087, VEGA 1/0125/18, KEGA 018-STU-4). This article was written thanks to the generous support under the Operational Program Integrated Infrastructure for the project: "Strategic research in the field of SMART monitoring, treatment and preventive protection against coronavirus (SARS-CoV-2) ", Project no. 313011ASS8, co-financed by the European Regional Development Fund. BB acknowledges The National Scholarship Programme of the Slovak Republic for the Support of Mobility of Students, PhD Students, University Teachers and Researchers; Tatra Bank Scholarship. IŠ acknowledges financial support from institutional sources of the Department of Inorganic Chemistry, Palacký University Olomouc, Czech Republic and from the Ministry of Education, Youth and Sports of the Czech Republic under the project CEITEC 2020 (LQ1601). The authors thank the platform SIV (Spectroscopie et Imagerie Vibrationnelle) at the University of Bordeaux, funded by the European Union (FEDER) and the Nouvelle Aquitaine region, for access to near-IR and UV Raman spectrometers. JP is grateful to the HPC centre at the Slovak University of Technology in Bratislava, which is a part of the Slovak Infrastructure of High Performance Computing (SIVVP project, ITMS code 26230120002, funded by the European region development funds, ERDF) and to Dr. Christoph Riplinger for enabling the calculation of Raman spectra within the development version of the ORCA software. The authors thank to Xavier Thompson for the participation on the synthesis of reported compounds.

\section{References}

1. a) P. Gütlich and H. A. Goodwin, Spin Crossover in Transition Metal Compounds IIII, Springer Berlin Heidelberg, Berlin, 2004; b) M. A. Halcrow, Spin-Crossover Materials: Properties and Applications, John Wiley \& Sons, Chichester, 2013; c) A. Bousseksou, G. Molnár, L. Salmon and W. Nicolazzi, Chem. Soc. Rev., 2011, 40, 3313; c) W. Nicolazzi and A. Bousseksou, C. R. Chimie, 2018, 21, 1060.

2. a) O. Kahn, J. Kröber and C. Jay, Adv. Mater. 4., 1992, 11, 718; b) J.-F. Létard, P. Guionneau and L. Goux-Capes, in Spin Crossover in Transition Metal Compounds III, ed. P. Gütlich and H. A. Goodwin, Springer Berlin Heidelberg, Berlin, 2004, pp. 221-249; c) Y. Garcia, V. Ksenofontov and P. Gütlich, Hyperfine Interact., 2002, 139, 543; d) G. Molnár, S. Rat, L. Salmon, W. Nicolazzi and A. Bousseksou, Adv. Mater., 2018, 30, 17003862; e) K. Senthil Kumar and M. Ruben, Coord. Chem. Rev., 2017, 346, 176. 
3. a) J. J. McGarvey and I. Lawthers, J. Chem. Soc. Chem. Commun., 1982, 906; b) I. Lawthers and J. J. McGarvey, J. Am. Chem. Soc., 1984, 106, 4280; c) J. J. McGarvey, H. Toftlund, A. H. R. Al-Obaidi, K. P. Taylor and S. E. J. Bell, Inorg. Chem., 1993, 32, 2469.

4. a) S. Decurtins, P. Gütlich, C.P. Köhler, H. Spiering and A. Hauser, Chem. Phys. Lett., 1984, 105, 1; b) A. Hauser, in Spin Crossover in Transition Metal Compounds II. Topics in Current Chemistry, ed. P. Gütlich and H. A. Goodwin, Springer Berlin Heidelberg, Berlin, 2004, pp. 155-198; c) G. Chastanet, M. Lorenc, R. Bertoni and C. Desplanches, C. R. Chim., 2018, 21, 1075; d) S. Hayami, Z.-Z. Gu, M. Shiro, Y. Einaga, A. Fujishima and O. Sato, J. Am. Chem. Soc., 2000, 122, 7126; e) I. Šalitroš and J. Pavlik, in Encyclopedia of Physical Organic Chemistry: Light-Induced Excited Spin State Trapping, ed. Z. Wang, U. Wille and E. Juaristi, John Wiley \& Sons, Hoboken, 2017, pp. 3083-3180.

5. a) M.-L. Boillot, J. Zarembowitch and A. Sour, in Spin Crossover in Transition Metal Compounds II, ed. P. Gütlich and H. A. Goodwin, Springer Berlin Heidelberg, Berlin, 2004, pp. 261-276; b) C. Roux, J. Zarembowitch, B. Gallois, T. Granier and R. Claude, Inorg. Chem., 1994, 33, 2273; c) J. Y. Lallemand, M. L. Boillot, J. Zarembowitch, J. Prunet and S. Chantraine, New J. Chem., 2002, 23, 179; d) M. M. Khusniyarov, Chem. Eur. J., 2016, 22, 15178.

6. a) Y. Hasegawa, K. Takahashi, S. Kume and H. Nishihara, Chem. Commun., 2011, 47, 6846; b) K. Takahashi, Y. Hasegawa, R. Sakamoto, M. Nishikawa, S. Kume, E. Nishibori and H. Nishihara, Inorg. Chem., 2012, 51, 5188; c) A. Tissot, M. L. Boillot, S. Pillet, E. Codjovi, K. Boukheddaden and L. M. Lawson Daku, J. Phys. Chem. C, 2010, 114, 21715; d) B. Rösner, M. Milek, A. Witt, B. Gobaut, P. Torelli, R. H. Fink and M. M. Khusniyarov, Angew. Chem. Int. Ed., 2015, 54, 12976; e) L. Poggini, M. Milek, G. Londi, A. Naim, G. Poneti, L. Squillantini, A. Magnani, F. Totti, P. Rosa, M. M. Khusniyarov and M. Mannini, Mater. Horizons, 2018, 5, 506; f) B. Brachňaková and I. Šalitroš, Chem. Pap., 2018, 72, 773.

7. V. Niel, J. M. Martinez-Agudo, M. C. Muñoz, A. B. Gaspar and J. A. Real, Inorg. Chem., 2001, 40, 3838.

8. a) Y. Garcia, V. Niel, M. C. Munoz and J. A. Real, in Spin Crossover in Transition Metal Compounds I, ed. P. Gütlich and H. A. Goodwin, Springer Berlin Heidelberg, Berlin, 2004, pp. 229-257; b) M. C. Muñoz and J. A. Real, Coord. Chem. Rev., 2011, 255, 2068; c) P. Gütlich, A. B. Gaspar and Y. Garcia, Beilstein J. Org. Chem., 2013, 9, 342; d) Z. P. Ni, J. L. Liu, M. N. Hoque, W. Liu, J. Y. Li, Y. C. Chen and M. L. Tong, Coord. Chem. Rev., 2017, 335, 28; e) C. Bartual-Murgui, N. A. Ortega-Villar, H. J. Shepherd, M. Carmen Muñoz, L. Salmon, G. Molnár, A. Bousseksou and J. A. Real, J. Mater. Chem., 2011, 21, 7217.

9. M. Ohba, K. Yoneda, G. Agustí, M. C. Muñoz, A. B. Gaspar, J. A. Real, M. Yamasaki, H. Ando, Y. Nakao, S. Sakaki and S. Kitagawa, Angew. Chem. Int. Ed. Engl., 2009, 48, 4767.

10. a) F. J. Muñoz Lara, A. B. Gaspar, D. Aravena, E. Ruiz, M. C. Muñoz, M. Ohba, R. Ohtani, S. Kitagawa and J. A. Real, Chem. Commun., 2012, 48, 4686; b) G. Agustí, R. 
Ohtani, K. Yoneda, A. B. Gaspar, M. Ohba, J. F. Sánchez-Royo, M. C. Muñoz, S. Kitagawa and J. A. Real, Angew. Chem. Int. Ed. Engl., 2009, 48, 8944.

11. P. D. Southon, L. Liu, E. A. Fellows, D. J. Price, G. J. Halder, K. W. Chapman, B. Moubaraki, K. S. Murray, J.-F. Létard and C. J. Kepert, J. Am. Chem. Soc., 2009, 131, 10998.

12. a) X. Bao, H. J. Shepherd, L. Salmon, G. Molnár, M.-L. Tong and A. Bousseksou, Angew. Chem. Int. Ed. Engl., 2013, 52, 1198; ; b) C. Bartual-Murgui, A. Akou, Ch. Thibault, G. Molnar, Ch. Vieu, L. Salmon and A. Bousseksou, J. Mat. Chem. C, 2015, 3, 1277; c) C. Bartual-Murgui, A. Akou, H. J. Shepherd, G. Molnár, J. A. Real, L. Salmon and A. Bousseksou, Chem. Eur. J, 2013, 19, 15036.

13. a) J. Park, D. Yuan, K. T. Pham, J.-R. Li, A. Yakovenko and H.-C. Zhou, J. Am. Chem. Soc., 2012, 134, 99; b) J. W. Brown, B. L. Henderson, M. D. Kiesz, A. C. Whalley, W. Morris, S. Grunder, H. Deng, H. Furukawa, J. I. Zink, J. Fraser Stoddart and O. M. Yaghi, Chem. Sci., 2013, 4, 2858; c) N. Yanai, T. Uemura, M. Inoue, R. Matsuda, T. Fukushima, M. Tsujimoto, S. Isoda and S. Kitagawa, J. Am. Chem. Soc., 2012, 134, 4501; d) A. Modrow, D. Zargarani, R. Herges and N. Stock, Dalton Trans., 2011, 40, 4217.

14. a) S. Garg, H. Schwartz, M. Kozlowska, A. B. Kanj, K. Müller, W. Wenzel, U. Ruschewitz and L. Heinke, Angew. Chem. Int. Ed Engl., 2019, 58, 1193; b) G. H. Clever, S. Tashiro and M. Shionoya, J. Am. Chem. Soc., 2010, 132, 9973; c) D. Samanta, J. Gemen, Z. Chu, Y. Diskin-Posner, L. J. W. Shimon and R. Klajn, Proc. Natl. Acad. Sci. U. S. A., 2018, 115, 9379; d) H. Dube, D. Ajami and J. Rebek Jr, Angew. Chem. Int. Ed Engl., 2010, 49, 3192; e) T. Kusukawa and M. Fujita, J. Am. Chem. Soc., 1999, 121, 1397.

15. C. Bartual-Murgui, L. Salmon, A. Akou, N. A. Ortega-Villar, H. J. Shepherd, M. C. Muñoz, G. Molnár, J. A. Real and A. Bousseksou, Chem. Eur. J, 2012, 18, 507.

16. a) G. M. Sheldrick, Acta Crystallogr. Sect. A, 2015, A71, 3; b) G. M. Sheldrick, Acta Crystallogr. Sect. C, 2015, C71, 3; c) O. Dolomanov, L. J. Bourhis, R. J. Gildea, J. A. K. Howard and H. Puschmann, J. Appl. Crystallogr., 2009, 42, 339; d) C. F. MacRae, I. Sovago, S. J. Cottrell, P. T. A. Galek, P. mcCabe, E. Pidcock, M. Platings, G. P. Shields, J. S. Stevens, M. Towler and P. A. Wood, J. Appl. Crystallogr., 2020, 53, 226.

17. a) F. Neese, WIREs Comput Mol Sci, 2018, 8, 33; b) F. Neese, WIREs Comput Mol Sci, 2012, 2, 73; c) S. Grimme, J. G. Brandenburg, C. Bannwarth and A. Hansen, J. Chem. Phys. 2015, 143, 054107; d) C. M. Breneman and K. B. Wiberg, J. Comput. Chem., 1990, 11, 361; e) J. P. Perdew, K. Burke, and M. Ernzerhof, Phys. Rev. Lett., 1996, 77, 3865; f) F. Weigend and R. Ahlrichs, Phys. Chem. Chem. Phys., 2005, 7, 3297; g) D. Andrae, U. Häußermann, M. Dolg, H. Stoll and H. Preuß, Theor. Chim. Acta, 1990, 77, 123; g) F. Neese, J. Comput. Chem., 2003, 24, 1740; i) J. P. Perdew, M. Ernzerhof and K. Burke, J. Chem. Phys., 1996, 105, 9982.

18. J.-F. Létard, J. Mater. Chem., 2006, 16, 2550.

19. a) M. Irie, Chem. Rev., 2000, 100, 1685; b) D. Gindre, A. Boeglin, A. Fort, L. Mager and K. D. Dorkenoo, Opt. Express, 2006, 14, 9896.

20. K. G. Yager and C. J. Barrett, J. Photochem. Photobiol. A Chem., 2006, 182, 250. 
21. a) H. Rau, in Photochromism, Molecules and Systems: Azo compounds, ed. H. Dürr and H. Bouas-Laurent, Elsevier, Amsterdam, 2003, pp. 165-192; b) H. M. D. Bandara and S. C. Burdette, Chem. Soc. Rev., 2012, 41, 1809.

22. G. Molnár, V. Niel, A. B. Gaspar, J.-A. Real, A. Zwick, A. Bousseksou and J. J. McGarvey, J. Phys. Chem. B, 2002, 106, 9701.

23. a) P. Hamm, S. M. Ohline and W. Zinth, J. Chem. Phys., 1997, 106, 519; b) L. Duarte, R. Fausto and I. Reva, Phys. Chem. Chem. Phys., 2014, 16, 16919.

24. a) V. Stepanić, G. Baranović and V. Smrečki, J. Mol. Struct., 2001, 569, 89; b) Z. Zhuang, J. Cheng, X. Wang, Y. Yin, G. Chen, B. Zhao, H. Zhang and G. Zhang, J. Mol. Struct., 2006, 794, 77.

25. a) C. H. Choi and M. Kertesz, J. Phys. Chem. A, 1997, 101, 3823; b) J. F. Arenas, I. L. Tocón, J. C. Otero and J. I. Marcos, J. Mol. Struct., 1995, 349, 29.

26. a) Z. Meić, T. Šuste, G. Baranović, V. Smrečki, S. Holly and G. Keresztury, J. Mol. Struct., 1995, 348, 229; b) C. Pecile and B. Lunelli, Can. J. Chem., 1969, 47, 243.

27. G. Agusti, S. Cobo, A. B. Gaspar, G. Molnár, N. O. Moussa, P. Á. Szilágyi, V. Pálfi, C. Vieu, M. Carmen Muñoz, J. A. Real and A. Bousseksou, Chem. Mater., 2008, 20, 6721.

28. C. M. Stuart, R. R. Frontiera and R. A. Mathies, J. Phys. Chem. A, 2007, 111, 12072.

29. H. Watanabe, Y. Okamoto, K. Furuya, A. Sakamoto and M. Tasumi, J. Phys. Chem. A, 2002, 106, 3318.

30. T. Egawa, K. Shinashi, T. Ueda, E. J. Ocola, W.-Y. Chiang and J. Laane, J. Phys. Chem. A, 2014, 118, 1103.

31. K. Furuya, K. Kawato, H. Yokoyama, A. Sakamoto and M. Tasumi, J. Phys. Chem. A, 2003, 107, 8251.

32. A. Akou, C. Bartual-Murgui, K. Abdul-Kader, M. Lopes, G. Molnár, C. Thibault, C. Vieu, L. Salmon and A. Bousseksou, Dalton Trans., 2013, 42, 16021.

33. a) W. Zhou, S. Grosjean, S. Bräse and L. Heinke, Z. Phys. Chem., 2018, 233, 15; b) X. Yu, Z. Wang, M. Buchholz, N. Füllgrabe, S. Grosjean, F. Bebensee, S. Bräse, C. Wöll and L. Heinke, Phys. Chem. Chem. Phys., 2015, 17, 22721; c) K. Müller, J. Helfferich, F. Zhao, R. Verma, A. B. Kanj, V. Meded, D. Bléger, W. Wenzel and L. Heinke, Adv. Mater., 2018, 30, 1706551; d) H. Meng, C. Zhao, M. Nie, C. Wang and T. Wang, ACS Appl. Mater. Interfaces, 2018, 10, 32607; e) Z. Wang, S. Grosjean, S. Bräse and L. Heinke, Chem. Phys. Chem., 2015, 16, 3779.

34. T. Fujino and T. Tahara, J. Phys. Chem. A, 2000, 104, 4203.

35. a) J.-M. Rodier, X. Ci and A. B. Myers, Chem. Phys. Lett., 1991, 183, 55; b) F. Capitani, M. Höppner, L. Malavasi, C. Marini, P. Dore, L. Boeri and P. Postorino, J. Phys. Conf. Series, 2017, 950, 042017. 


\section{Graphical abstract}

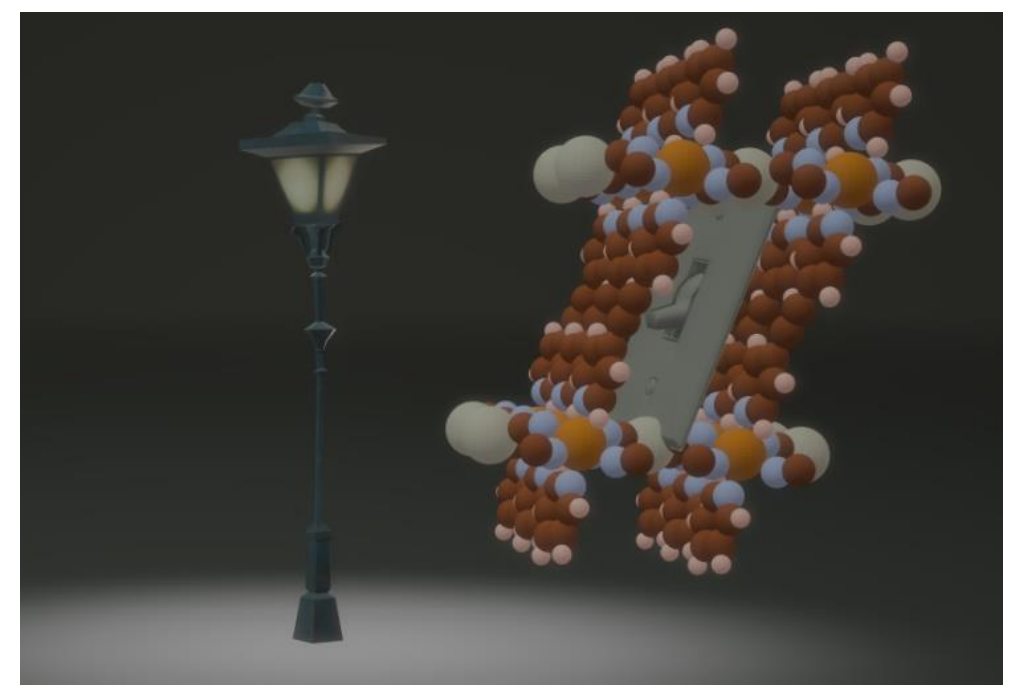

The introduction of photoactive guest molecules into a spin crossover 3D metal organic framework alters the switchable properties of both host and guest. 